\title{
OPTIONS FOR QUANTITATIVE ASSESSMENT OF TYPES OF COMMERCIAL REAL ESTATE LEASES
}

\author{
TOMAS GINEVIČIUS
}

\begin{abstract}
A B S T R A C T
Facing increasing business volumes and internationalisation, office lease issue is becoming increasingly relevant to business enterprises. They become an integral part of the business which determines the outcome of commercial activities. Current assessment methodologies for types of office leases are flawed because they lack comprehensiveness and they are not linked to the objective of a lease, that is improvement of business deliverables. The methods for quantitative assessment of lease types are flawed. The objective of this article is developing a hierarchical system of indicators in connection with commercial real estate (office) leases adapted for quantitative assessment using multi-criteria methods. As a result of the research, it has been obtained that such system contains three categories: economic, premises and environmental. 12 indicators fall into the first one, 24 - into the second and $16-$ into the third one.
\end{abstract}

KEY WORDS

commercial real estate (office) lease, multi-criteria assessment methods

DOI: 10.1515/emj-2016-0006
Corresponding author:

Tomas Ginevičius Vilnius Gediminas Technical University Faculty of Transport Engineering, Lithuania

e-mail: Tomas.Ginevicius@vgtu.It

\section{INTRODUCTION}

Many reference sources aimed at examining the issue of commercial real estate lease first of all stress that the issue is of importance. The main reason is the fact that premises of the mentioned intended use have a significant effect on the deliverables of commercial activities such as competitiveness, sales volumes and profit.

Offices are distinguished as a separate class of commercial real estate. The analysis of reference sources which give an overview of the existing situation demonstrates that the demand for them will be increasing in both the short-term and long-term perspective. It is due to two reasons. First, owing to the improving economic situation of the country, the number of Lithuanian business enterprises that are interested in having suitable office premises will be increasing. Secondly, foreign investors optimising their activities show growing interest in the Central European and Baltic states turning away from India and other Asian countries. Hence, the issue of real estate (office), $(\operatorname{CRE}(0))$ lease is of significant relevance from the practical perspective. Owing to its nature, the issue and the solution thereto are also complicated from a scientific point of view because it is a very sophisticated and complex phenomenon. This sophistication and complexity originate in the fact that the CRE(o) lease is a characteristic of wide variety of aspects in reality, that is economic lease conditions, environment of premises subject to lease, nature of the premises, and so on. Indicators showing the mentioned aspects have been expressed in a wide variety of dimensions. What is more, the nature of any variations thereof also differs, that is decreasing values of certain indicators improve whereas of others aggravate the situation. Hence, there emerges not only a practical, but also a scientific issue of how to develop a system of indicators based on such a huge number of them that would adequately reflect the 
types of commercial real estate (office) leases and how to adapt such a system for quantitative assessment to rank all types of leases by their suitability from the tenant's perspective.

The objective of this article is to develop a hierarchical system of indicators in connection with commercial real estate (office) leases adapted for quantitative assessment using multi-criteria methods.

\section{SIGNIFICANCE OF COMMERCIAL REAL ESTATE (OFFICES) TO BUSINESS DEVELOPMENT}

Business enterprises are established to carry out commercial - economic activities and achieve certain economic deliverables. They can attain the mentioned objective only in the case where the production process is sustainable, smooth and focused. This is guaranteed by the management system of the enterprise. As a general rule it is developed on the basis of management functions to be implemented by management personnel specialising in these functions. One of the essential conditions for effective functioning of such personnel is suitable environment. In market economy conditions, each enterprise usually had an administrative building for these purposes, hovewer having and maintaining such buildings or premises is no longer useful from the economic sense. Hence, the lease of office premises became prevalent. These days leased office premises have become an integral part of the business. Practice has shown that they should be perceived as one of the significant factors that determine the success of economic activities of a business enterprise (Fawcett \& Chadwick, 2007; Fawcett \& Rigby, 2009; Investa Properties Limited, 2006; Martinac et al., 2011; Van de Wetering \& Wyatt, 2011).

Demand for offices and requirements therefore are determined by certain factors (Fig. 1).

Domestic demand for office lease means the demand of business enterprises of the country. It is created when enterprises:

- establish subsidiaries;

- develop business into new areas;

- seek to improve office environment;

- bring business together into one space;

- seek to improve their image.

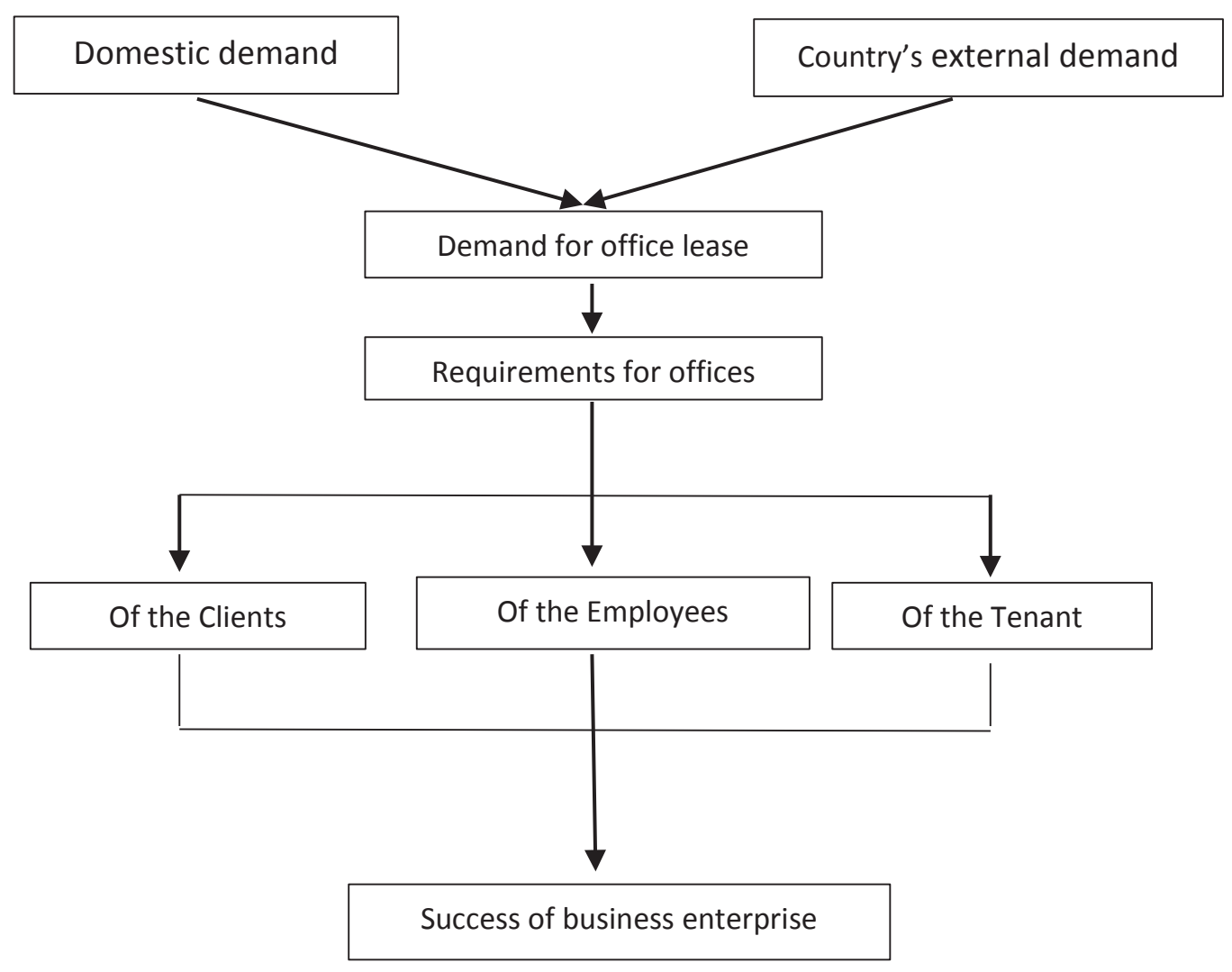

Fig. 1. Effect of $\operatorname{CRE}(\mathrm{o})$ on the success of business 
External demand means the demand of foreign enterprises that invest in the country. In the market knowing that offices have a significant impact on business deliverables, increasingly higher requirements have been raised for leased premises, that is for their technical characteristics, quality and variety of services offered by the landlord, environment of workplaces, et cetera (French \& Wieseman, 2003; Nase et al., 2013; Pagouztri et al., 2003). Hence, the choice of a prospective tenant is determined, to a great extent, not only by a few major criteria, but a totality thereof which include such aspects as: location of the building where the office premises are situated; exterior; interior; areas; expansion possibilities; ergonomic solutions (Sacramento et al., 2013; Appel - Meulenbroek et al., 2011; Choi et al., 2012; Saari et al., 2006; Warren, 2003; Levy \& Peterson, 2013).

The relevance of commercial real estate (office) lease as an issue is evidenced in its supply and demand trends. Increasing office lease supply means constructing new business centres and other premises intended for office lease. Essentially, it is a response to existing situation of the demand or forecast (Tab. 1).
- majority of the methodologies are aimed at examining the rent cost of real estate (RE) and the influencing key factors thereof (French \& Wiseman, 2003; Nase et al., 2013; Pagourtri et al., 2003; Fuerst \& McAllister, 2010; Eichholtz et al., 2009, 2010);

- there is no systematic approach towards creating a system of RE lease indicators (AppelMeullenbroek et al., 2011; Choi et al., 2012; Saari et al., 2006; Warren, 2003);

- the focus is on the RE market and its factors, but not the lease (Zhang, 2015; Cupal, 2014; Fan et al., 2014).

Other flaws characteristic to the proposed methodologies include: few of them are essentially unsuitable for developing a system facilitating the lease decision-making; a significant percentage seek to examine the sale/purchase of offices as an investment opportunity, but not the lease; systems of indicators which are the basis for choosing a certain type of lease disregard many important aspects. To sum up current or proposed CRE(o) lease methodologies, the following underlying flaws can be noted: first, they lack comprehensiveness, a systematic

Tab. 1. Supply of new offices in Vilnius City, in thousand sq $m$

\begin{tabular}{|l|c|c|c|c|c|c|c|c|c|c|c|}
\hline YEAR & 2006 & 2007 & 2008 & 2009 & 2010 & 2011 & 2012 & 2013 & 2014 & 2015* & 2016* \\
\hline AREA, IN THOUSAND SQ M & 16.04 & 28.21 & 46.42 & 89.31 & 33.30 & 2.50 & 18.21 & 14.70 & 19.90 & 37.72 & 42.22 \\
\hline
\end{tabular}

Source: Newsec Baltic.

Other major cities in Lithuania (Kaunas, Klaipeda) and Estonia as well as Latvia are in a similar situation as Vilnius City. Data provided in Table 1 demonstrate that since 2012 the demand for offices has been growing; hence, the issues in connection with the lease thereof have been increasingly relevant.

In order to choose suitable business premises, a variety of aspects have to be considered. This makes office lease a very complex scientific issue. It is no coincidence that a wide selection of assessment methods for types of leases is suggested in the references. All of them are based on the indicators characterising types of leases.

\section{DEVELOPING A SYSTEM OF COMMERCIAL REAL ESTATE (OFFICE) LEASE INDICATORS}

An overview of assessment methods for types of commercial real estate (office) leases pointed out, along with advantages, the following major flaws: approach towards developing a system of lease indicators; second, the systems of indicators are not linked with the objective of lease, that is improvement of business deliverables; third, the weight of lease indicators is not appreciated.

Commercial real estate (office) lease, as a phenomenon, manifests itself in reality through many aspects. The need to take them into consideration is determined by the wish of a prospective tenant to rent the premises that would contribute to their business success to the greatest extent. Hence, the requirements for the premises are derived from the above. The premises have to be attractive in the sense of their interior, geographic location as well as surrounding environment. What is more, they must facilitate the modern businessrelated operations. On the other hand, the tenants are mindful of the rent cost, pollution and safety of the area, and so on. The question is whether it is possible to find an indicator that integrates the huge variety of lease aspects in such a controversial situation. 
Seeking for a solution, each and every of the mentioned aspects needs to be seen as a criterion aimed at reflecting the aspect in a quantitative manner. In such a case, we will be able to understand a complicated and complex phenomenon of CRE(o) lease the light of the totality of those criteria and as a system. In order to develop it, first of all, it is necessary to make a list of criteria or indicators based on the references, expert survey and other sources. It includes indicators that are significant, not very significant and insignificant to the CRE(o) lease. phenomena is limited because they are reflected by a large number of indicators what makes determining of their significance impossible.

In the second case, considering that CHP indicators are interlinked, the basis for developing the system is the assumption that the links have different strength. This leads to the idea that the most interlinked indicators reflect the same aspect of the CHP. Such indicators can be combined into one group. If there are more indicators than an expert assessing their weight can deal with, this

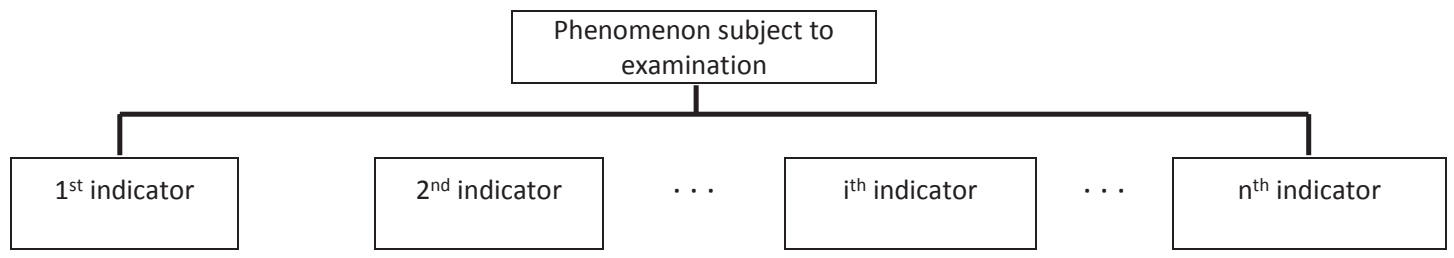

Fig. 2. Single-level system of indicators of the phenomenon subject to examination

Then, the organisation of this list, that is removal of insignificant indicators, should be carried out (Ginevičius \& Podvezko, 2005).

When the composition of indicators left after organising the list has been determined, one should proceed with developing a system. The underlying goal of this procedure is to develop a system of indicators suitable for quantitative assessment of types of office leases (Ginevičius, 2009). Analysis of reference sources enable the development of such system to be expressed not as a subjective and unreasoned process, but as a structured sequence of logical acts. It is determined, to a great extent, by the choice of concept. Two possible approaches become apparent: first, where it is considered that indicators characterising phenomenon (CHP) reflect it directly, hence, they are relatively independent of each other; second, where it is considered that the indicators of the system are interlinked (some directly whereas others indirectly). Indirectly linked indicators reflect the analysed phenomenon from its aspect where they are included to (Ginevičius, 2009).

In the first case, considering that the indicators of the system are relatively independent and reflect the phenomenon directly, the development of the system results in a single-level system of indicators (Fig. 2).

Using such a system of indicators for quantitative assessment of the state of complicated and complex group is in turn divided into separate smaller sections. This structuring process is finished when every such group contains a number indicators sufficient for expert evaluation of the weight thereof (Ginevičius, 2007, 2009).

The outcome of such grouping of CHP indicators is a hierarchically structured system of indicators adapted for quantitative assessment of their state.

Based on the mentioned procedure, the goal was to develop a system of commercial real estate (office) lease indicators suitable for quantitative assessment of their types.

A list of possible CRE(o) lease indicators was developed on the basis of reference and other sources as well as expert survey. It includes 59 indicators in total: significant, not very significant and insignificant ones from an office lease perspective.

In order to "organise the list”, a methodology based on the methods of mathematical statistics was invoked (Ginevičius \& Podvezko, 2005). After removing the insignificant indicators, the system has 52 indicators. Such a number is too large for expert evaluation of the significance of indicators. Hence, the system of indicators had to be structured. The analysis of its content demonstrated that the indicators were interlinked and that the links were of different strength. Stronger links exist between 


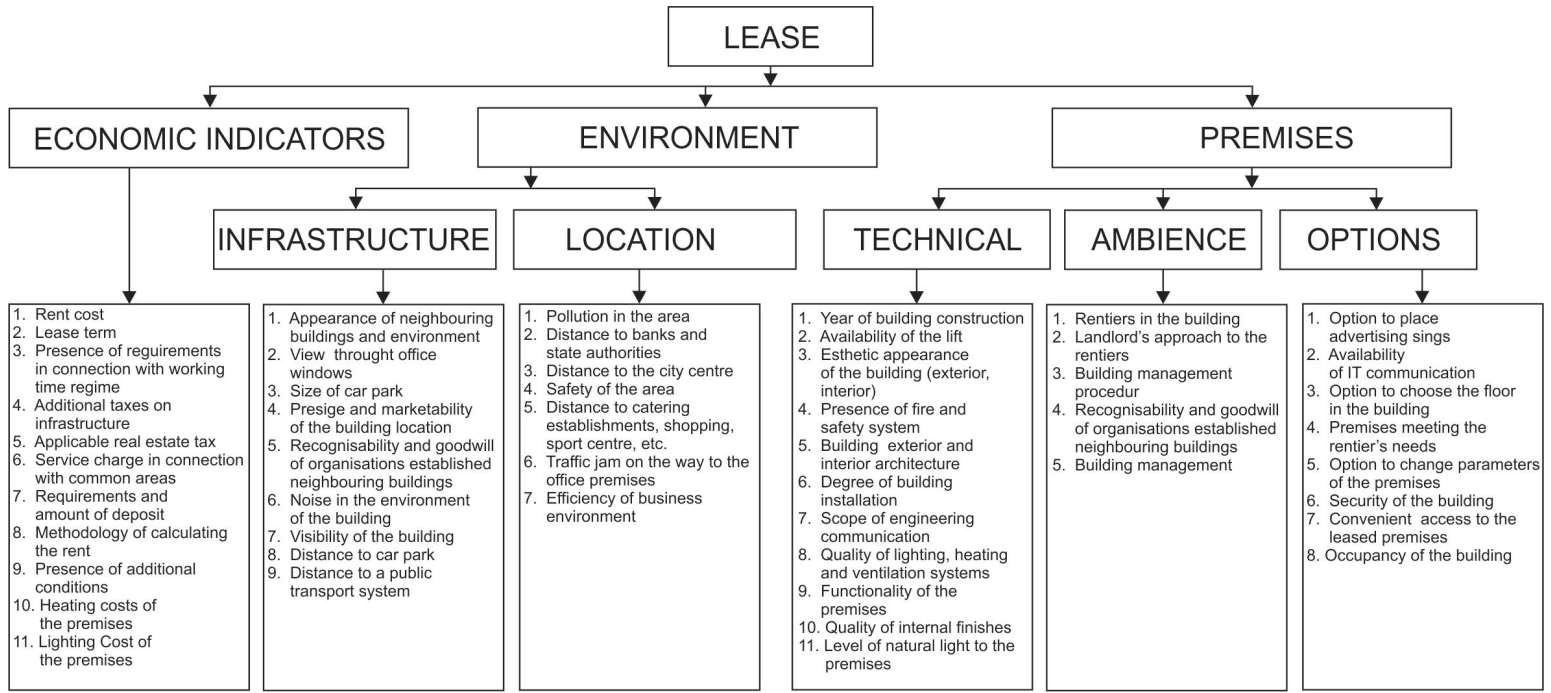

Fig. 3. Hierarchically structured system of commercial real estate (office) lease indicator

those indicators which define the same aspect of office lease. Three of such aspects became apparent: economic lease conditions; type of premises subject to lease and the environment of the building where premises subject to lease are located in. Having grouped the indicators by their characteristics, the outcome is that the economic category includes 12 indicators, premises - 24 and environmental 16 indicators. The question is whether the system of indicators structured in this manner is suitable for quantitative assessment. Reference sources state, without a deeper scientific substantiation, that the number of indicators to be assessed simultaneously for determining their weight should not exceed 10-12 (Ginevicius, 2007; 2009).

We see that only the category of economic indicators meets the mentioned condition. Thus the other two categories require a more in depth structuring.

Analysis of indicators in connection with the premises has demonstrated that they can be divided into three related groups. The first group defines technical facilities of the premises, the second - their ambience and the third one - the options. 11 indicators fell into the first group, 5 into the second and 8 indicators into the third one. The category of environmental indicators has been subdivided into two groups: infrastructure and location. The first group contains 9 and the second one -7 indicators. Hence, the number of indicators within each group does not exceed 12; therefore, it is possible to assess their weight.
A hierarchically structured system of commercial real estate (office) lease indicators adapted for quantitative assessment of lease types is the following (Fig. 3).

\section{CONCLUSIONS}

Owing to improving economic situation, the issue of having suitable office premises is becoming increasingly relevant to business enterprises of the country. The demand therefore is also increased by the growing interest of foreign investors in the Central European and Baltic states. Office premises have become an integral part of business because they have a significant effect on the business deliverables, that is competitiveness, profitability, and so on.

Overview of assessment methods for types of commercial real estate (office) leases has revealed the following flaws: first, they lack comprehensiveness, a systematic approach towards developing a system of lease indicators; second, the systems of indicators are not linked with the objective of lease, that is improvement of business deliverables; third, quantitative assessment methods of such indicators are flawed.

Types of CRE (o) leases manifest themselves in reality through many indicators. In order to prioritise the types it is necessary to combine all of these indicators into one general measure. 
The underlying issue which is faced in the course of quantitative assessment of lease types is developing a suitable system of indicators. To this extent a list of lease indicators has to be made first of all, then insignificant indicators need to be removed therefrom and the remainder structured hierarchically in a manner that the number of indicators subject to simultaneous assessment does not exceed $10-12$ for the purpose of assessing their weight.

The hierarchically structured system of CRE (o) indicators contains three categories: economical, premises and environmental. 12 indicators fall into the first one, 24 - into the second and 16 - into the third one. To make the system of indicators suitable for quantitative assessment, the premises category has been divided into three sections: technical facilities (11 indicators), ambience (5 indicators) and options (8 indicators). The environmental category of indicators has been divided into two sections: infrastructure (9 indicators) and location (7 indicators). The resulting final system of indicators has been adapted for quantitative assessment.

\section{LITERATURE}

Appel-Meulenbroek, R., Groenen, P., \& Janssen, I. (2011). An end-user's perspective on activity-based office concepts. Journal of Corporate Real Estate, 13(2), 122-135.

Choi, J.-H., Loftness, V., \& Aziz, A. (2012). Post-occupancy evaluation of 20 office buildings as basis for future IEQ standards and guidelines. Energy and Buildings, 46, 167-175.

Cupal, M. (2014). The Comparative Approach Theory for Real Estate Valuation. Social and Behavioral Sciences, 109, 19-23.

Eichholtz, P., Kok, N., \& Quigley, J. (2009). Doing well by doing good? An analysis of financial performance of green office buildings in the USA, RICS Report. London, Great Britain: Royal Institution of Chartered Surveyors. Retrieved from http://www. srmnetwork.com/pdf/whitepapers/Financial_Performance_of_Green_Office_Buildings_RICS_ Mar09.pdf

Eichholtz, P., Kok, N., \& Quigley, J. M. (2010). Doing well by doing good? Green office buildings. American Economic Review, 100(5), 2492-2509.

Fan, G., Huszár, Z., \& Zhang, W. (2013). The Relationships between Real Estate Price and Expected Financial Asset

Risk and Return: Theory and Empirical Evidence. Real Estate Finance and Economics, 6, 568-595.

Fawcett, W., \& Chadwick, A. (2007). Space-time management and office floorspace demand: Applied experience and mathematical simulations. Journal of Corporate Real Estate, 9(1), 5-24.
Fawcett, W., \& Rigby, D. (2009). The interaction of activity, space and cost variables in office workstation sharing. Journal of Corporate Real Estate, 11(1), 38-51.

French, N., \& Wiseman, G. (2003). The price of space: the convergence of value in use and value in exchange. Journal of Property Investment \& Finance, 21(1), 23-30.

Fuerst, F., \& Grandy, A.-M. (2012). Rational expectations?: Developer behaviour and development cycles in the central London office market. Journal of Property Investment \& Finance 30(2), 159-174.

Fuerst, F., \& McAllister, P. (2011). Eco-labeling in commercial office markets: Do LEED and Energy Star offices obtain multiple premiums? Ecological Economics, 70(6), 1220-1230.

Ginevičius, R. (2007). Hierarchical Structuring of Processes and Phenomena. Busineess: Theory and Practice, 8(1), 14-18.

Ginevičius, R. (2009). Some Problems of Quantitative Evaluation of the State of Social-Economic Systems. Busineess: Theory and Practice, 10(2), 69-83.

Ginevičius, R., \& Podvezko, V. (2005). Generation of a Set of Evaluation Criteria. Busineess: Theory and Practice, 6(4), 199-207.

Investa Properties Limited. (2006). Green lease guide - for commercial office tenants. Sydney, Australia: Investa Property Group. Retrieved from http://www.sustainability.vic.gov.au/resources/documents/green_lease. pdf

Levy, D., \& Peterson, G. (2013). The effect of sustainability on commercial occupiers' building choice. Journal of Property Investment \& Finance, 31(3), 267-284.

Martinac, I., Azar, M., Choy, M., Miller, M., \& Nilsson, A. (2011). Energy saving in commercial rental properties - Innovative stakeholder relationships and contracting models - CERBOF Project \#20, Final report. Centre for Energy and Resource Efficiency in the Built Environment (CERBOF). Retrieved from http://www.cerbof. se/documents/Projekt/Rapporter/Slutrapport_CERBOF_20.pdf

Nase, I., Berry, J., \& Adair, A. (2013). Real estate value and quality design in commercial office properties. Journal of European Real Estate Research, 6(1), 48-62.

Pagourtzi, E., Assimakopoulos, V., Hatzichristos, T., \& French, N. (2003). Real estate appraisal: a review of valuation methods. Journal of Property Investment \& Finance, 21(4), 383-401.

Saari, A., Tissari, T., Valkama, E., \& Seppänen, O. (2006). The effect of a redesigned floor plan, occupant density and the quality of indoor climate on the cost of space, productivity and sick leave in an office building - A case study. Building and Environment, 41(12), 1961-1972.

Sacramento, C. A., Fay, D., \& West, M. A. (2013). Workplace duties or opportunities? Challenge stressors, regulatory focus, and creativity. Organizational Behavior and $\mathrm{Hu}$ man Decision Processes, 121(2), 141-157. 
Warren, C. (2003). New working practice and office space density: a comparison of Australia and the UK. Facilities, 21(13/14), 306-314.

Wetering Van de, J., \& Wyatt, P. (2011). Office sustainability: occupier perceptions and implementation of policy. Journal of European Real Estate Research, 4(1), 29-47.

Zhang, X. (2015). Green real estate development in China: State of art and prospect agenda - A review. Renewable and Sustainable Energy Reviews, 47, 1-13. 